\title{
In Vitro Anti-Candida Activity of the Hydroalcoholic Extracts of Heracleum persicum Fruit Against Phatogenic Candida Species
}

\author{
Batool Sadeghi Nejad ${ }^{1}$; Mahsa Rajabi ${ }^{1}$; Ali Zarei Mamoudabadi ${ }^{1,2}$; Majid Zarrin ${ }^{1, *}$ \\ ${ }^{1}$ Department of Medical Mycology, Medical School, Ahvaz Jundishapur University of Medical Sciences, Ahvaz, IR Iran \\ ${ }^{2}$ Health Research Institute, Infectious and Tropical Diseases Research Centre, Ahvaz Jundishapur University of Medical Sciences, Ahvaz, IR Iran \\ ${ }^{*}$ Corresponding author: Majid Zarrin, Department of Medical Mycology, Medical School, Ahvaz Jundishapur University of Medical Sciences, Ahvaz, IR Iran. Tel: +98-6113330074; Fax: \\ +98-6113332036, E-mail:mjzarrin@yahoo.co.uk
}

Received: October 21, 2012; Revised: January 28, 2013; Accepted: February 26, 2013

\begin{abstract}
Background: Nowadays Candida albicans has become resistant to the toxic and expensive commercial anti-Candida drugs. Therefore, investigation for new anti-fungal agents is necessary.

Objectives: The purpose of this survey was to investigate the in vitro anti-Candida activity of the hydroalcoholic extracts of Heracleum persicum fruit.

Materials and Methods: The plant ingredients were extracted using 80\% ethanol and the extract was screened against 46 isolated pathogenic Candida species such as C. albicans, C. glabrata and C. tropicalis by agar well diffusion method.

Results: The minimum inhibitory concentration (MIC) values at 24 and 48 hours were $0.625-20 \mu \mathrm{g} / \mu \mathrm{L}$ for C. albicans, $0.625-40 \mu \mathrm{g} / \mu \mathrm{L}$ for C. glabrata, and $5.0-20 \mu \mathrm{g} / \mu \mathrm{L}$ for C. tropicalis.

Conclusions: The results of this survey confirmed that tested plant extract had a potential anti-Candida activity. Hence, it is suggested to isolate and identify its active compounds in future.
\end{abstract}

Keywords: Heracleum; Extract; Candida

\section{Background}

In the past two decades, the prevalence of candidiasis has been increased. Candida species are able to create superficial and systemic infections. Candida albicans is an opportunistic pathogen, causing mycoses in immunocompromised patients as well as long-term antibiotic users (1). Also, other Candida species such as C. glabrata, C. parapsilosis, C. tropicalis and C. krusei are among the oral mucosal lesions suspected agents in AIDS patients (2). Herbal Medicines have been used as alternative drugs in developing countries. Brazil, Cuba, India, Jordan and Mexico are examples of countries with various herbs as well as a potent folklore in using medicinal plants for their antimicrobial and antifungal benefits (3-6). Heracleum persicum (in the Apiaceae family), known as Golpar in Persian, is vernacular to Iran. It grows wildly in humid mountainous regions and is used in soups and stews. Ten out of 70 species (7) of $H$. persicum are known in Iran (8). H. persicum fruit is extensively used as spice and the young stems are also used for making pickles. Chemical compounds such as Pimpinellin, isopimpinellin, bergapten, isobergapten and six furanocoumarins have been reported to be extracted from its roots $(9,10)$.

\section{Objectives}

Because of the high usage of $H$.persicum fruit as an herbal medicine in the Iranian culture beside its analgesic activity, we decided to survey the hydroalcoholic extract of $H$. persicum fruit, assessing its anti-Candida activity by agar well diffusion method.

\section{Materials and Methods}

\subsection{Plant Ingridients and Preparation of Hydroalcoholic Extract}

H.persicum fruits were purchased from a local market in Ahvaz, Iran. For preparation of hydroalcoholic extract, 10 $\mathrm{g}$ air-dried and powdered fruit of $H$. persicum was macerated with $100 \mathrm{~mL}$ of $80 \%$ ethanol and methanol on a rotary shaker for 72 hours, filtered, and then the solution was evaporated in the room temperature. Dried hydroalcoholic extract was stored in a sterile glass bottle at $-20^{\circ} \mathrm{C}$ until future assays. One gram of the dried hydroalcoholic extract of $H$. persicum was dissolved in $5 \mathrm{~mL}$ dimthyl sulphoxide (DMSO, 100\%) to a final concentration of $200 \mu \mathrm{g} /$ $\mu \mathrm{L}$ as stock, and serial double fold dilutions were pre-

Implication for health policy/practice/research/medical education:

Finding alternative antifungal drugs is necessary for effective remedy of Candida infections. Thus, our aim was to search the medicinal plants used in Iranian herbal medications against three Candida species, to confirm other observations obtained from the previous researches.

Copyright @ 2014,Ahvaz Jundishapur University of Medical Sciences; Published by Kowsar Corp. This is an open-access article distributed under the terms of the Creative Commons Attribution License, which permits unrestricted use, distribution, and reproduction in any medium, provided the original work is properly cited. 
pared using sterile distilled water from $0.078-40 \mu \mathrm{g} / \mu \mathrm{L}$ according to the previous literature (11).

\subsection{Yeast Inoculum Preparation}

A total of 47 Candida spp. isolates including C. albicans [29], C. glabrata [10], and C. tropicalis [7], isolated from oral swabs samples, were selected. Candida spp. isolates were inoculated into Sabouraud dextrose broth (SDB, Merk, Germany) and grown overnight on a rotary shaker at room temperature. Then cells were washed three times with sterile distilled water and adjusted by the same solvent to yeast inoculum of $10^{6} \mathrm{CFU} / \mathrm{mL}$ (0.5 Mac-Farland standard).

\subsection{Positive and Negative Controls}

The commercial antifungal drugs such as clotrimazole $\operatorname{disc}(10 \mu \mathrm{g} / \mathrm{disc})$ and nystatin disc (100 IU/disc) were used as positive controls and DMSO was used as negative control.

\subsection{Anti-Candida Assay}

Anti-Candida activities of the hydroalcoholic extracts of $H$. persicum fruit were assayed against Candida spp. isolates by agar well diffusion according to Perez et al. method (12). One hundred microliter of yeast inoculum $\left(10^{6}\right.$ cells $\left./ \mathrm{mL}\right)$ was uniformly spread onto Sabouraud dextrose agar medium (SDA, Merck, Germany) using a bent glass rod. Then five wells of $7 \mathrm{~mm}$ diameter were punched by a borer into the SDA medium and filled with $100 \mu \mathrm{L}$ of two-fold serial dilutions of plant extracts as well as sterile DMSO 100\% as negative control. Plates were incubated for 24 hours at $37^{\circ} \mathrm{C}$. Anti-Candida activity was determined by measuring the zone of inhibition. Experiments were carried out three times. Two positive controls such as clotrimazole and nystatin discs were placed in the plate. The lowest concentration of a tested plant extract exhibiting a clear zone, was considered as the minimum inhibitory concentration (MIC).

\section{Results and Discussion}

In the current study, we surveyed the anti-Candida activity of the hydroalcoholic extracts of $H$. persicum fruit against three different Candida species (C. albicans, $C$. tropicalis and C. glabrata). The results are summarized in Figure 1 and Tables 1 and 2. The ethanolic and methanolic extracts of the tested plants showed anti-Candida activities against $C$. albicans $(n=29)$, C. tropicalis $(n=10)$, and $C$. glabrata $(\mathrm{n}=7)$. The strongest activity was seen against $C$. albicans with a range of $12-21 \mathrm{~mm}$ inhibition zones and 0.625 - $20 \mu \mathrm{g} / \mu \mathrm{L}$ MIC values; the ethanolic extract of the tested plant has more anti-Candida effects at $0.625 \mu \mathrm{g} / \mu \mathrm{L}$ compared to the methanolic extract at $2.5 \mu \mathrm{g} / \mu \mathrm{L}$. Similar results were reported by other researchers with different medicinal plants (13). According to Mimica-Dukic et al. study (14) among tested Candida spp. isolates, C. albicans was the most sensitive tested Candida spp. to Mentha piperita L. oil, which was in agreement with our results. The lowest concentration of the tested plant showed a potential anti-Candida activity against C. albicans and C. glabrata, while the highest concentration showed a weak inhibitory effect against $C$. tropicais . Furthermore, previous studies reported that the essential oil of $H$. persicum has moderate anti-Candida activity (15). In Iranian traditional medicine, $H$. persicum fruit was used as a carminative and pain relieving herbal drug $(16,17)$. Review of literature reported that coumarins were known to be responsible for antifungal activity of many of the medicinal plants $(18,19)$. It was suggested that furanocoumarins, isolated from the fruit of $H$. persicum (10), were the cause of anti-Candida activity of this plant. Candida species are in the normal flora of healthy people, while they can cause superficial mycosis and invasive infections in immunocompromised patients (20). During the past 20 years, the incidence of infection by pathogenic fungi has been increased; most of which were infected by Candida spp. that can change the superficial mycosis to invasive infections. C. albicans has been a major factor of morbidity and mortality in immunocompromised patients, but other Candida spp. such as C. glabrata and C. krusei have expanded in the recent years (21 - 23).

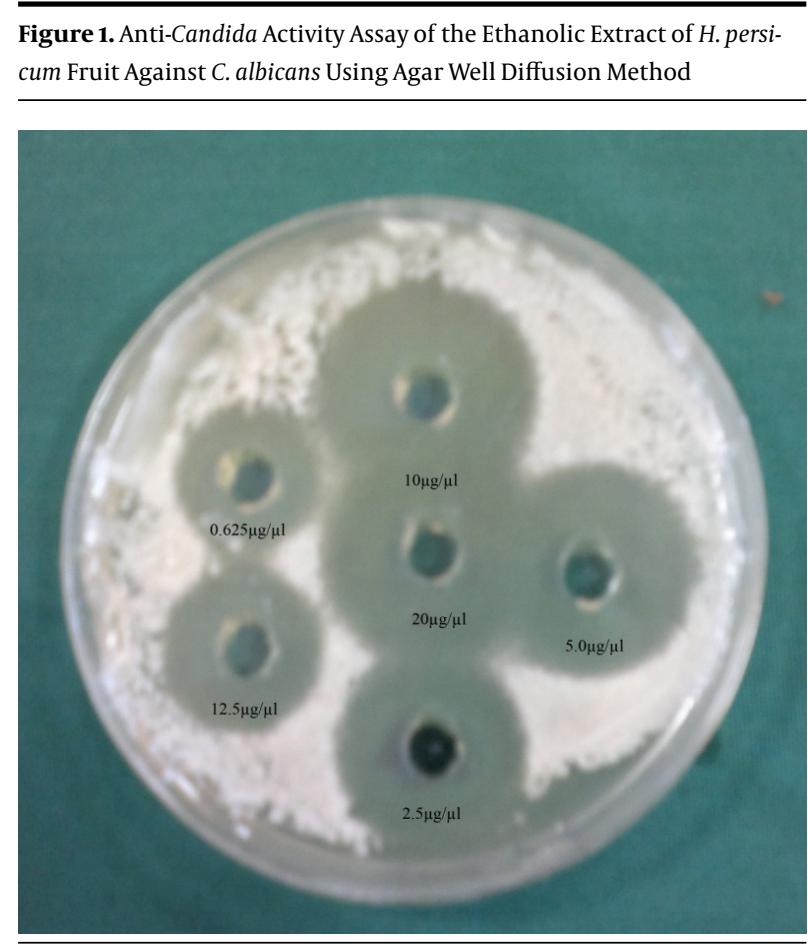

Decreasing dilutions ranging from 0.625 to $20 \mu \mathrm{g} / \mu \mathrm{L} ; \mathrm{MIC}=0.625 \mu \mathrm{g} / \mu \mathrm{L}$. 
Sadeghi Nejad B et al.

\begin{tabular}{|c|c|c|c|}
\hline \multirow[t]{2}{*}{ Antifungal Agents } & \multicolumn{3}{|c|}{ Candida spp. Isolates $\mathrm{MIC}^{\mathrm{a}}, \mu \mathrm{g} / \mu \mathrm{L}$} \\
\hline & C. albicans, No. 29 & C.glabrata, No. 10 & C. tropicalis, No. 7 \\
\hline \multicolumn{4}{|l|}{ Treatments $^{\mathrm{b}}$} \\
\hline Ethanolicextract of H. persicum & $0.625-20$ & $0.625-40$ & $5-20$ \\
\hline Methanolic extract of $H$. persicum & $5-20$ & $2.5-20$ & $5-20$ \\
\hline \multicolumn{4}{|l|}{ Positive controls } \\
\hline Clotrimazole & $0.0078 \mu \mathrm{g} / \mu \mathrm{L}$ & $-\mathrm{C}^{-}$ & - \\
\hline Nysatatin & $0.0039 \mu \mathrm{g} / \mu \mathrm{L}$ & -- & - \\
\hline
\end{tabular}

\footnotetext{
a Abbreviation: MIC, minimal inhibitory concentration.

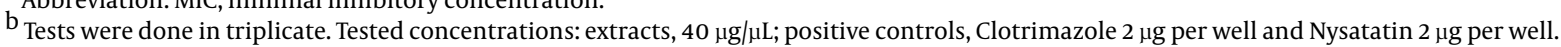

c no data is provided.
}

\begin{tabular}{|c|c|c|c|}
\hline \multirow[t]{2}{*}{ Antifungal Agents } & \multicolumn{3}{|c|}{ Candida spp. Isolates Inhibition Zone Diameter, mm } \\
\hline & C. albicans, No. 29 & C. glabrata, No. 10 & C. tropicalis, No. 7 \\
\hline \multicolumn{4}{|l|}{ Treatments $^{\mathrm{a}}$} \\
\hline Ethanolic extract of H.persicum & $10-18$ & $11-18$ & $8-15$ \\
\hline Methanolic extract of H.persicum & $12-21$ & $12-20$ & $11-18$ \\
\hline \multicolumn{4}{|l|}{ Positive controls } \\
\hline Clotrimazole & 20 & $--\mathrm{b}$ & - \\
\hline Nysatatin & 22 & -- & - \\
\hline
\end{tabular}

\footnotetext{
$\mathrm{a}$ Tests were done in triplicate. Tested concentrations: extracts, $40 \mu \mathrm{g} / \mu \mathrm{L}$; positive controls, Clotrimazole $10 \mu \mathrm{g} /$ disc and Nysatatin $100 \mathrm{IU} / \mathrm{disc}$.

$\mathrm{b}$ no data is provided.
}

Therefore, there is an urgent necessity for finding alternative antifungal drugs for effective treatment of Candidal infections.

\section{Acknowledgements}

The authors are grateful to the Department of Medical Mycology, Ahvaz Jundishapur University of Medical Sciences, Ahvaz, IR Iran, for providing laboratory facilities.

\section{Authors' Contribution}

All authors contributed significantly in this research.

\section{Financial Disclosure}

There is not conflict of interest in this research.

\section{Funding/Support}

This study was supported by authors.

\section{References}

1. Zhang Z, ElSohly HN, Jacob MR, Pasco DS, Walker LA, Clark AM Natural products inhibiting Candida albicans secreted aspartic proteases from Tovomita krukovii. Planta Med. 2002;68(1):49-54.

2. Krcmery V, Barnes AJ. Non-albicans Candida spp. causing fungaemia: pathogenicity and antifungal resistance. J Hosp Infect.
2002;50(4):243-60

3. Martinez MJ, Betancourt J, Alonso-Gonzalez N, Jauregui A. Screening of some Cuban medicinal plants for antimicrobial activity. $J$ Ethnopharmacol.1996;52(3):171-4.

4. Mahasneh AM, El-Oqlah AA. Antimicrobial activity of extracts of herbal plants used in the traditional medicine of Jordan. JEthnopharmacol.1999;64(3):271-6.

5. Ahmad I, Beg AZ. Antimicrobial and phytochemical studies on 45 Indian medicinal plants against multi-drug resistant human pathogens. J Ethnopharmacol. 2001;74(2):113-23.

6. Rehder VLG, Machado ALM, Delarmelina C, Sartoratto A, Duarte MCT, Figueira GM. [Chemical and the antimicrobial activity of essential oil of two species of Origanum]. Revista Brasileira de Plantas Medicinais. 2004;6:67-71.

7. Evans WC. Trease and Evans Pharmacognosy. 14th edLondon: WB Saunders Company Limited; 1996.

8. Mozaffarian VA. Dictionary of Iranian Plant Names.Tehran: Farhang Moaser; 1996.

9. Aynehchi Y, Aliabadi Z, Salehi-Surmaghi MH. Furanocoumarines in roots of Heracleum persicum. Acta Horticulture. 1978;73(1):103107.

10. Merijanian A, Colasurdo T, Samtak P, Ullrich J, Spagnuolo J. The furanocomarins of Heracleum persicum L. Revista Latinoamericana de Qumica.1980;11:51-53.

11. Sadeghi-Nejad B, Saki J, Khademvatan S, Nanaei S. In vitro antileishmanial activity of the medicinal plant-Satureja khuzestanica Jamzad. J Med Plant Res. 2011;5(24):5912-5915.

12. Perez C, Pauli M, Bazerque P. An antibiotic assay by the well agar method. Acta Biologiae et Medicine Experimentalis. 1990;15:113-115.

13. Najafi S, Nejad BS. Screening of Pogostemon parviflorus Benth. for anti-Candida activity. Afr J Microbiol Res. 2011;5(6):657-60.

14. Mimica-Dukic N, Bozin B, Sokovic M, Mihajlovic B, Matavulj M. 
Antimicrobial and antioxidant activities of three Mentha species essential oils. Planta Med. 2003;69(5):413-9.

15. Naeiny A, Nassery M, Kamalnejas M, Khshzaban F, Rajabian T, Esmaeilzadeh $\mathrm{H}$, et al. In vitro survey of anticandidial effects of the essential oils and fifty extracts of Iranian herbal medicine. J Med plants. 2001;38:163-172.

16. Naraghi M. Medicinal Flowers and Plants.Tehran: Amir Kabir Publications; 1972

17. Zargari A. Medicinal plants. 4 th ed. Tehran: Tehran University Publications; 1990.

18. Sadeghi-Nejad B, Deokule SS. Antidermatophytic activities of Ixora brachiata Roxb. Afr J Biochem Res. 2009;3(10):344-348.
19. Cowan MM. Plant products as antimicrobial agents. Clin Microbiol Rev. 1999;12(4):564-82.

20. Abad MJ, Ansuategui M, Bermejo P. Active antifungal substances from natural sources. Arkivoc. 2007;7:116-145.

21. Kupfahl C, Ruppert T, Dietz A, Geginat G, Hof H. Candida species fail to produce the immunosuppressive secondary metabolite gliotoxin in vitro. FEMS Yeast Res. 2007;7(6):986-92.

22. Pincus DH, Orenga S, Chatellier S. Yeast identification--past, present, and future methods. Med Mycol. 2007;45(2):97-121.

23. Segal E. Candida, still number one--what do we know and where are we going from there? Mycoses. 2005;48 Suppl 1:3-11. 